\title{
INFLUÊNCIA DA IMERSÃO EM ÁGUA NA RESISTÊNCIA MECÂNICA DE MISTURAS SOLO-GRITS COMPACTADAS E CURADAS COM VISTAS A APLICAÇÕES EM ESTRADAS FLORESTAIS ${ }^{1}$
}

\author{
Reginaldo Sérgio Pereira ${ }^{2}$, Carlos Cardoso $\mathrm{Machado}^{3}$, Dario Cardoso de $\mathrm{Lima}^{4}$, Carlos Alexandre Braz de \\ Carvalho $^{4}$ e Danuse Machado Pires ${ }^{5}$
}

\begin{abstract}
RESUMO - Avaliou-se o efeito da imersão em água dos corpos-de-prova sobre a resistência mecânica de misturas solo-grits. Trabalhou-se com dois solos da cidade de Viçosa, localizada na Zona da Mata Norte de Minas Gerais, Brasil, respectivamente de texturas predominantemente argilosa e arenosa e com o resíduo sólido industrial grits, um subproduto da indústria de celulose. Determinaram-se os parâmetros de resistência mecânica California Bearing Ratio (CBR) e Resistência à Compressão Não-Confinada (RCNC) de corpos-de-prova compactados nas energias de compactação referentes aos ensaios Proctor intermediário e Proctor modificado, com teores de grits na faixa de 4 a $28 \%$ e períodos de cura de 0,7 e 28 dias. Com relação ao parâmetro CBR, os ensaios foram realizados segundo a metodologia tradicional (imersão em água dos corpos-de-prova por 96 horas) e sem a imersão em água, visando determinar possíveis perdas na capacidade-suporte das misturas. No que tange ao parâmetro compressão não-confinada, os ensaios foram realizados em obediência à norma brasileira para misturas solo-cimento (imersão em água durante quatro horas antes da ruptura dos corpos-de-prova) e sem a fase de imersão em água. Os resultados indicaram que a imersão em água dos corpos-de-prova influenciou significativamente a resistência mecânica das misturas solo-grits, que foram dependentes do tipo de ensaio empregado, tipo de solo, teor de grits, energia de compactação e período de cura.
\end{abstract}

Palavras-chave: Estabilização de solos, estradas florestais e resíduo grits.

\section{INFLUENCE OF WATER SUBMERSION ON THE MECHANICAL STRENGTH OF COMPACTED AND CURED SOIL-GRITS MIXTURES FOR FOREST ROADS APPLICATIONS}

\begin{abstract}
This paper address the influence of water submersion on mechanical strength parameters of soil-grits specimens. Two residual soils, predominantly clayey and sandy soils from the city of Viçosa, located in the State of Minas Gerais, "Zona da Mata Norte”, Brazil, and waste from cellulose industry were used in the study. The laboratory testing program consisted of CBR (California Bearing Ratio) and UCS (Unconfined Compression Strength) of specimens prepared with waste contents ranging from 4 to $28 \%$, compacted at the intermediate and modified compaction efforts, and cured during 0,7 and 28 days. Laboratory tests were performed as follow: (i) CBR: tests were performed following the standard procedure, i.e. after 4 days water submersion before specimen penetration, and without submersion; and (ii) UCS: tests were performed following the Brazilian standard procedure, i.e. after 4 hours specimen submersion before testing, and without water submersion. The laboratory testing program data support that water submersion significantly influenced the tested mechanical strength parameters, which were dependent of the type of assay and soil, percentage of grits waste, compaction effort and cure.
\end{abstract}

Keywords: Soil stabilization, forest roads and grits waste.

\footnotetext{
${ }^{1}$ Recebido em 06.07.2006 e aceito para publicação em 11.03.2007.

${ }^{2}$ Departamento de Engenharia Florestal da Universidade de Brasília. E-mail: <reginaldosp@ unb.br>.

${ }^{3}$ Departamento de Engenharia Florestal da Universidade Federal de Viçosa. E-mail: <machado@ufv.br>.

${ }^{4}$ Departamento de Engenharia Civil da Universidade Federal de Viçosa. E-mail:<declima@ufv.br>; <cabraz@ufv.br>.

${ }^{5}$ Bolsista de Iniciação Científica da FAPEMIG.
} 


\section{INTRODUÇÃO}

O aumento substancial, a cada ano, da quantidade de subprodutos ou de resíduos gerados pelos diversos setores industriais da economia mundial e nacional muito tem contribuído para a elevação da poluição de ecossistemas, inclusive os marinhos. Isso está relegado ao fato de que grande quantidade desses rejeitos não possui processo de descarte adequado, seja pela falta de tecnologia prática e menos onerosa ou de tecnologias de reaproveitamento dentro do próprio processo industrial ou em outros setores.

Pesquisadores em todo mundo tentam encontrar soluções para a problemática, indo desde a obtenção de tratamentos que eliminem por completo os rejeitos até soluções que envolvam a aplicação destes em outras áreas. Rohde et al. (2001) destacaram a reciclagem ou utilização de subprodutos industriais como os responsáveis pela redução das agressões ao meio ambiente, causadas pela disposição de resíduos em aterros ou pela emissão de gases poluentes. Esses autores acrescentaram também que, em se tratando de obras rodoviárias, ocorre a diminuição da exploração predatória de recursos naturais (jazidas de agregados). Nesses tipos de obras, uma das variáveis condicionantes na execução, conforme destacado por Senço (1997), é a análise de custos entre as soluções disponíveis, situação em que o solo local exerce papel determinante na tomada de decisão.

Trindade et al. (2005) destacaram que o emprego das técnicas de estabilização de solos com material alternativo em substituição aos tradicionais materiais de jazidas de empréstimo pode trazer significativas reduções nos custos de manutenção das vias florestais. Entretanto, isso requer um criterioso programa de ensaios laboratoriais de estudos de estabilização química envolvendo solos regionais e resíduos industriais. Exemplo disso foi o trabalho de Machado et al. (2003a) com o alcatrão, resíduo da carbonização da madeira de eucalipto, que foi testado na estabilização de solos da microrregião de Viçosa, Minas Gerais.

Em prosseguimento à linha de pesquisa mencionada, uma série de estudos laboratoriais vem sendo desenvolvidos na Universidade Federal de Viçosa com o resíduo da indústria de celulose denominado grits Machado et al. (2003b), baseados em dados da resistência mecânica de um Latossolo Vermelho-Amarelo, típico da microrregião de Viçosa, MG, apontaram o grits como potencialmente utilizável na estabilização de solos para estradas florestais, quando em mistura com esse resíduo e submetido a gradientes térmicos e compactado. Machado et al. (2004), em estudos ambientais de misturas solo-grits, concluíram que estas não constituem material perigoso do ponto de vista de poluição.

Este trabalho teve como objetivo avaliar o efeito da imersão em água dos corpos-de-prova sobre os parâmetros de resistência mecânica California Bearing Ratio (CBR) e Resistência à Compressão Não-Confinada (RCNC) das misturas, compactadas e curadas, de dois solos típicos da Zona da Mata Norte de Minas Gerais com o resíduo industrial grits, para fins de aplicação em pavimentação de estradas florestais.

\section{MATERIAL E MÉTODOS}

\subsection{Caracterização do material utilizado}

Os materiais empregados neste estudo constituíramse de dois solos típicos da microrregião de Viçosa, Zona da Mata Norte de Minas Gerais, e do resíduo grits, gerado na indústria de celulose. Os solos denominados por solo 1 e solo 2 tratam, respectivamente, de um Latossolo Vermelho-Amarelo com textura argiloareno-siltosa e de um saprolítico de textura areno-argilosiltosa, representando esses exemplares dois extremos do sistema de classificação rodoviário americano Transportation Research Board (TRB), os quais são, respectivamente, A-7-5 (20) e A-2-4 (0). Pela proposição brasileira Miniatura Compactado Tropical (MCT), o solo 1 possui comportamento de material laterítico argiloso, grupo LG' do sistema; análogo, o solo 2 referese a um material não-laterítico arenoso pertencente ao grupo NA'. As amostras foram coletadas em taludes de estradas situadas nas proximidades da usina de pré-misturado a frio da Prefeitura Municipal de Viçosa, em se tratando do solo 1, e na localidade denominada Vila Secundino, Campus da UFV, caso do solo 2.

O resíduo grits, utilizado em teores de 4 até $28 \%$, foi cedido pela empresa Celulose Nipo Brasileira (Cenibra S.A.), sendo armazenado em tambores hermeticamente fechados no laboratório de geotecnia da UFV, para posterior utilização nos ensaios laboratoriais. O interesse pelo seu uso na estabilização de solos se deveu em primeira instância, à presença de $\mathrm{CaO}$ (óxido de cálcio) no quantitativo de $20 \%$ e, também, por ser um material não reutilizável dentro do processo industrial de extração de celulose, sendo sua disposição final feita, atualmente, 
em aterros industriais, gerando riscos ambientais passíveis de ocorrência; são gerados aproximadamente 10.500 t/ano desse resíduo, em se tratando exclusivamente da empresa Cenibra S.A. O grits é classificado como classe II (material não inerte) pela ABNT (1987), referente à NBR 10.004. Informações a respeito de possíveis impactos ambientais decorrentes da utilização de resíduos industriais em pavimentos de estradas florestais podem ser encontradas em Pereira et al. (2003).

\subsection{Preparação das misturas}

Nas misturas solo-grits, adicionou-se o resíduo nos teores de 4, 8, 12, 16, 20, 24 e 28\% em relação ao peso de solo seco, fez-se a homogeneização dessa massa, adicionou-se água com posterior homogeneização e procedeu-se ao acondicionamento das misturas em sacos plásticos impermeáveis, considerando-se os tempos ótimos decorridos entre a mistura e a compactação determinados por Pereira et al. (2006) com as misturas solo-grits, antes da execução dos ensaios. Esses tempos ótimos foram os que se associaram aos maiores valores de resistência mecânica e, em laboratório, resultaram em: (i) 4 h nas misturas solo 1-grits; e (ii) compactação imediatamente após o processamento das misturas solo 2grits.

\subsection{Programa de ensaios laboratoriais}

O programa de ensaios abrangeu a seguinte seqüência de determinações nos solos e nas misturas solo-grits: (i) peso específico aparente seco máximo $\left(\gamma_{\text {dmax }}\right)$ e umidade ótima $\left(\mathrm{W}_{\mathrm{ot}}\right)$, através dos ensaios de compactação realizados nas energias dos ensaios Proctor intermediário e modificado (DNIT, 1994b); (ii) capacidade de suporte $\mathrm{CBR}_{\text {1ponto }}$ (DNIT, 1994a) com corpos-de-prova moldados no teor de umidade ótima $\left(\mathrm{W}_{\mathrm{ot}}\right)$ da energia de compactação intermediária; (iii) resistência à compressão não-confinada (RCNC) com corpos-deprova moldados, em camadas e por processo dinâmico, no teor de umidade ótima $\left(\mathrm{W}_{\mathrm{ot}}\right)$ das energias de compactação intermediária e modificada (DNIT, 1994d).

$\mathrm{O}$ índice $\mathrm{CBR}_{1 \text { ponto }}$ das misturas solo-grits compactadas foi determinado de duas formas: (i) curaramse os corpos-de-prova pelo período de sete dias em câmara climatizada com umidade relativa do ar superior a 95\%, e executou-se a imersão em água dos corposde-prova em tanque CBR por $96 \mathrm{~h}$, antes do rompimento em prensa, conforme prescrição do ensaio tradicional; e (ii) curaram-se também os corpos-de-prova pelo período de sete dias em câmara climatizada com umidade relativa do ar superior a 95\%, e rompeu-os em prensa.

Para a realização dos ensaios de RCNC, os corposde-prova $(\phi=5 \mathrm{~cm} \mathrm{e} \mathrm{h}=10 \mathrm{~cm})$ foram moldados em tréplica, para cada tratamento, e apresentados os resultados das médias das tensões de ruptura, admitindose uma tolerância de $\pm 10 \%$ em torno da média. Caso contrário, três novos corpos-de-prova foram novamente confeccionados. A determinação desse índice para as misturas solo-grits abrangeu: (i) cura de corpos-deprova, devidamente embalados e identificados, nos períodos de 0,7 e 28 dias, em câmara climatizada com umidade relativa do ar superior a 95\%, imersão em água por $4 \mathrm{~h}$ (DNIT, 1994c) e rompimento em prensa com velocidade de $1,25 \mathrm{~mm} / \mathrm{min}$; e (ii) cura de corpos-deprova, devidamente embalados e identificados, nos períodos de 0,7 e 28 dias, em câmara climatizada com umidade relativa do ar superior a $95 \%$ e rompimento em prensa com velocidade de $1,25 \mathrm{~mm} / \mathrm{min}$.

\section{RESULTADOS E DISCUSSÃO}

\subsection{Resultados dos ensaios de compactação}

Os resultados apresentados no Quadro 1 indicam que a adição de grits promoveu aumento nos valores de peso específico aparente seco máximo e redução nos valores de umidade ótima do solo 1 , na compactação tanto da energia intermediária quanto modificada. Comportamento contrário foi observado quando se adicionaram grits ao solo 2, ou seja, redução nos valores de $\gamma_{\text {dmax }}$ e aumento nos valores de $\mathrm{W}_{\text {ot }}$. Pode-se associar o comportamento do solo 1 à ocorrência de reações de troca catiônica entre o grits e a fração fina desse solo, o que proporcionou agregação de partículas e redução das exigências de umidade para se atingir determinado arranjo de partículas, resultando em densidades secas mais elevadas. Essa afirmação está baseada nas constatações de Lima et al. (1993), que descreveram que os solos de granulometria fina reagem bem com a cal $(\mathrm{CaO})$, ocorrendo trocas catiônicas responsáveis por efeitos de floculações, aglomerações que afetam, beneficamente, a sua trabalhabilidade, plasticidade e propriedades de caráter expansivo. A adição de um material (grits) de peso específico dos sólidos inferior ao do solo 2 proporcionou menores valores de peso específico aparente seco máximo.

R. Árvore, Viçosa-MG, v.31, n.3, p.479-486, 2007 
Quadro 1 - Parâmetros ótimos de compactação das misturas solo-grits Table 1 - Optimum compaction parameters for soil-grits mixtures

\begin{tabular}{|c|c|c|c|c|c|c|c|c|}
\hline \multirow{4}{*}{$\begin{array}{c}\text { Grits } \\
(\%)\end{array}$} & \multicolumn{8}{|c|}{ Misturas } \\
\hline & \multicolumn{4}{|c|}{ Solo 1-Grits } & \multicolumn{4}{|c|}{ Solo 2-Grits } \\
\hline & \multicolumn{2}{|c|}{ Energia Intermediária } & \multicolumn{2}{|c|}{ Energia Modificada } & \multicolumn{2}{|c|}{ Energia Intermediária } & \multicolumn{2}{|c|}{ Energia Modificada } \\
\hline & $\gamma_{\text {dmáx }}\left(\mathrm{kN} / \mathrm{m}^{3}\right)$ & $\mathrm{W}_{\mathrm{ot}}(\%)$ & $\gamma_{d m a ́ x}\left(\mathrm{kN} / \mathrm{m}^{3}\right)$ & $\mathrm{W}_{\mathrm{ot}}(\%)$ & $\gamma_{\text {dmáx }}\left(\mathrm{kN} / \mathrm{m}^{3}\right)$ & $\mathrm{W}_{\mathrm{ot}}(\%)$ & $\gamma_{d m a ́ x}\left(\mathrm{kN} / \mathrm{m}^{3}\right)$ & $\mathrm{W}_{\mathrm{ot}}(\%)$ \\
\hline$O$ & 14,58 & 28,87 & 15,37 & 26,49 & 18,33 & 11,38 & 19,01 & 9,90 \\
\hline 4 & 15,04 & 27,85 & 15,57 & 25,72 & 18,21 & 11,47 & 19,02 & 9,98 \\
\hline 8 & 15,01 & 27,55 & 15,85 & 24,47 & 18,14 & 11,57 & 18,86 & 10,24 \\
\hline 12 & 14,89 & 27,37 & 15,97 & 24,28 & 18,17 & 11,58 & 18,84 & 10,22 \\
\hline 16 & 15,14 & 27,06 & 16,03 & 23,39 & 18,15 & 11,92 & 18,81 & 10,33 \\
\hline 20 & 15,08 & 26,29 & 16,14 & 23,09 & 18,16 & 11,96 & 18,74 & 10,41 \\
\hline 24 & 15,20 & 25,85 & 16,16 & 22,75 & 18,13 & 12,37 & 18,59 & 11,29 \\
\hline 28 & 15,45 & 24,45 & 16,19 & 22,57 & 18,04 & 12,41 & 18,65 & 11,26 \\
\hline
\end{tabular}

\subsection{Influência da imersão em água na resistência mecânica}

Devido ao confinamento dos corpos-de-prova no cilindro California, em todas as misturas solo-grits não foram observadas perdas de integridade de corposde-prova devido à imersão em água, no ensaio CBR. Nas misturas solo 1-grits, as perdas máximas nos valores de CBR, devido à imersão em água, foram de $20 \%$, conforme ilustrado na Figura 1 (a). Com relação às misturas solo 2-grits (Figura 1b), o teor de grits foi determinante no comportamento dessas misturas, na imersão em água, ou seja, foram observadas perdas nos valores de CBR de 43, 17 e 5\%, respectivamente, nos teores de 4,8 e $12 \%$ de grits, a partir do teor de $16 \%$ de resíduo. Os valores de CBR dos corposde-prova das misturas solo 2-grits, imersas em água, suplantaram os valores de CBR dessas mesmas misturas compactadas, curadas e rompidas, porém sem a fase de imersão em água. Os incrementos nos valores de CBR foram de 9, 39, 78 e 136\% referentes, respectivamente, aos teores de 16, 20, 24 e $28 \%$ de grits. Explicação provável para o fato pode estar na melhoria das propriedades hidráulicas do resíduo grits devido à imersão em água, que é dependente do seu teor e do tipo de solo que está sendo empregado, a exemplo do que acontece com as misturas solocimento.


$\square$ Ensaios com fase de 4 dias de imersão em água
Ensaios sem fase de imersão em água
$\square$ Perdas (\%) nos valores de CBR

Figura 1 - Influência da imersão em água nos valores de CBR das misturas solo-grits.

Figure 1 - Influence of water submersion on CBR values for soil-grits mixtures.

R. Árvore, Viçosa-MG, v.31, n.3, p.479-486, 2007 
Nas Figuras 2 e 3, encontram-se ilustrados os resultados dos ensaios de compressão não-confinada das misturas solo-grits compactadas, curadas e imersas ou não em água. Os resultados dos ensaios executados para as misturas solo 1-grits, elucidados na Figura 2, prescrevem que: (i) o emprego da energia de compactação modificada proporcionou maiores perdas nos valores de RCNC, devido à fase de imersão em água por 4 h, em comparação com a energia intermediária; casos de desfragmentação ou perda de integridade total dos corpos-de-prova foram notados nas misturas com 20 e $28 \%$ de grits compactadas na energia modificada e submetidas às curas de 0 e 7 dias; com cura de 28 dias, nesses mesmos teores, as misturas solo 1-grits suportaram a imersão em água em razão,
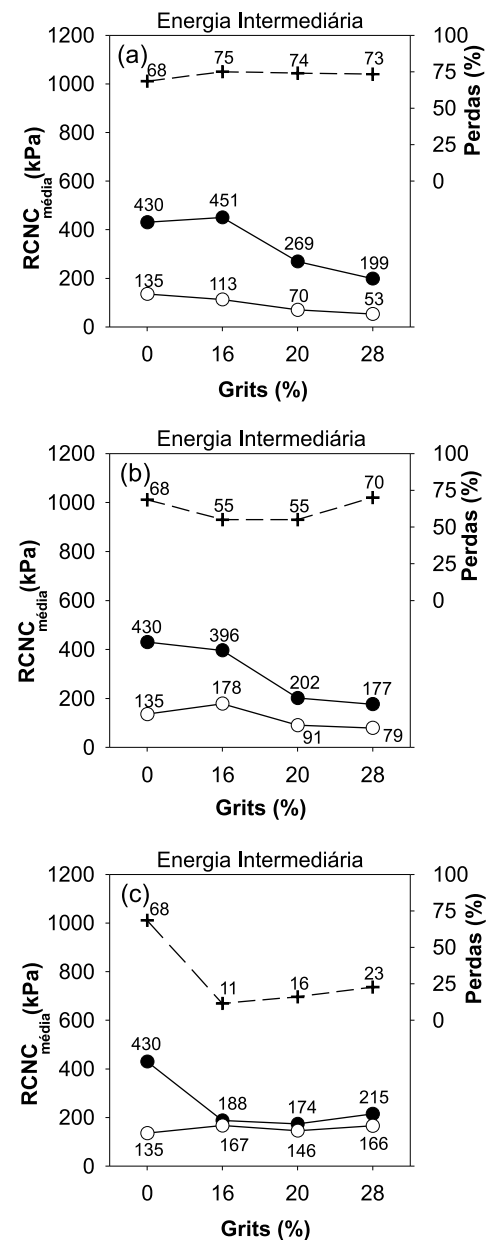

*NSI - Não suportaram a imersão. provavelmente, da ocorrência das reações pozolânicas entre os argilominerais presentes na fração fina do solo 1 e o $\mathrm{CaO}$ presente no grits, possibilitando maior cimentação das partículas do solo. Lima et al. (1993) descreveram que as propriedades de engenharia das misturas solo-cal são dependentes das condições de cura, visto que evoluem, dinamicamente, com o período de cura, em razão do desenvolvimento de reações pozolânicas; e (ii) o período de cura nessas misturas foi o fator determinante do comportamento destas, visto que, quanto maior a cura, menores as perdas de resistência devido à imersão em água, sendo no período de cura de 28 dias observadas as menores perdas nos valores de RCNC.
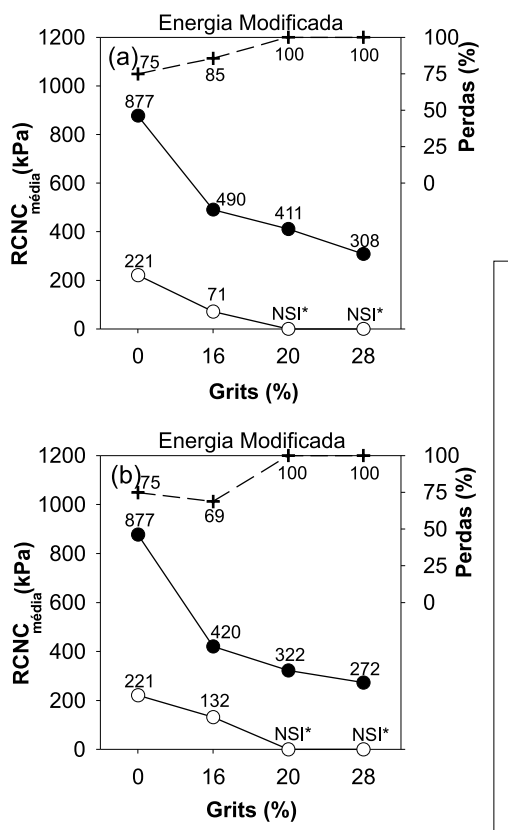

0

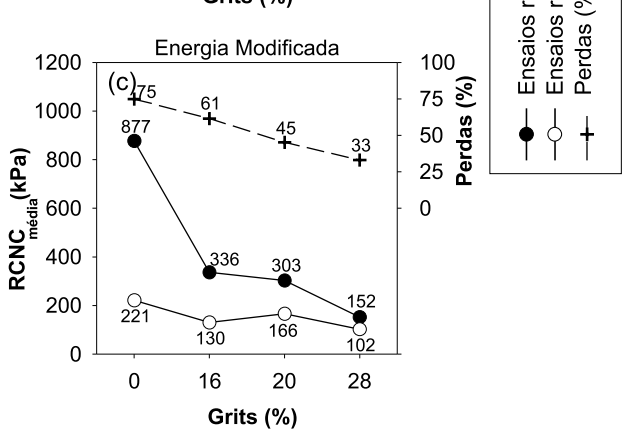

Figura 2 - Influência da imersão em água nos valores de RCNC das misturas solo 1-grits: (a) sem cura, (b) cura de sete dias e (c) cura de 28 dias.

Figure 2 - Influence of water submersion on UCS values for soil 1-grits mixtures: (a) no cure; (b) cure for 7 days; and (c) cure for 28 days. 



*NSI - Não suportaram a imersão.

Figura 3 - Influência da imersão em água nos valores de RCNC das misturas solo 2-grits: (a) sem cura (b) cura de sete dias e (c) cura de 28 dias.

Figure 3 - Influence of water submersion on UCS values for soil 2-grits mixtures: (a) no cure; (b) cure for 7 days; and (c) cure for 28 days.

Nota-se, pela Figura 3, que o solo 2, em sua forma natural, compactado tanto na energia intermediária quanto na modificada, não suportou a imersão em água, devido à falta de parcela coesiva entre as suas partículas, havendo perda total de integridade dos corpos-deprova. Quando se adicionou grits ao solo 2, foram observados os seguintes comportamentos dessas misturas, também ilustrados na Figura 3: (i) quando não submetidas a períodos de cura (Figura 3a), somente a mistura solo $2+16 \%$, compactada na energia intermediária, suportou a imersão em água, com perda de $38 \%$ no valor de RCNC, obtida de corpos-de-prova sem a fase de imersão, ocorrendo perda de integridade dos corpos-de-prova nos demais tratamentos; (ii) essas mesmas misturas submetidas ao período de cura de sete dias (Figura 3b) apontaram o teor de $28 \%$ de grits como o único que não levou os corpos-de-prova à perda de integridade, devido à imersão em água, sendo observadas perdas mínimas nos valores de RCNC de 4 e $0,5 \%$, respectivamente, na compactação nas energias intermediária e modificada; e (iii) o período de cura de 28 dias (Figura 3 c) levou as misturas solo 2-grits, compactadas na energia intermediária, a perdas nos valores de RCNC de 36, 52 e 68\%, respectivamente, nos teores de 16,20 e $28 \%$ de grits, não sendo observados nesse esforço de compactação nenhuma perda total de integridade dos corpos-de-prova; nas misturas compactadas na energia modificada e considerando- 
se a cura de 28 dias, somente a mistura com $28 \%$ de grits suportou a imersão em água, com perda de $44 \%$ no valor de RCNC.

Ressalta-se que, em se tratando das misturas solo 2grits, nem sempre os corpos-de-prova apresentaram amolecimento ou perda de integridade total, conforme ilustração da Figura 4, entretanto, a danificação de seu volume impossibilitou a ruptura em prensa de compressão simples. As perdas de integridade média nos corposde-prova classificados como Não Suportaram a Imersão (NSI) foram: (i) misturas compactadas na energia intermediária: 30, 45 e 50\%, respectivamente, nos teores de grits de 16, 20 e 28\%; e (ii) misturas compactadas na energia modificada: tiveram perdas de integridade imediatas, com menos de 30 min após a imersão, verificando-se a formação de bolhas, seguidas por deterioração, e perdas de 50 até $100 \%$ dos corpos-de-prova.


Corpos-de-Prova Com 100\% de Integridade
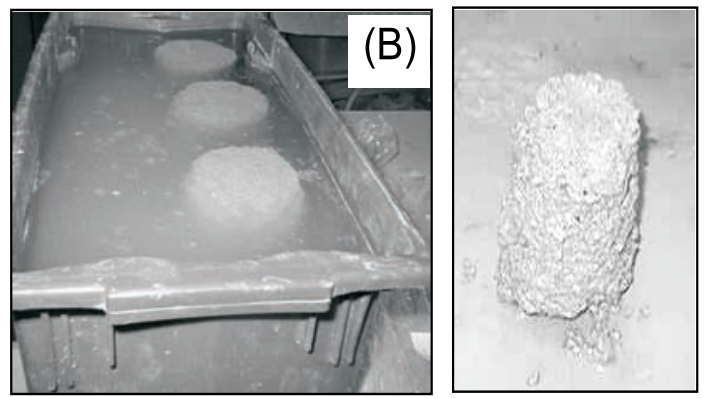

Corpos-de-Prova com Perda Parcial de Integridade de $70 \%$

Figura 4 - Perda de integridade das misturas solo 2-grits, compactadas e curadas, devido à imersão em água: (a) misturas compactadas na energia intermediária e curadas a 28 dias e (b) misturas compactadas na energia modificada.

Figure 4-Integrity detriment for soil 2-grits mixtures, compacted and cured, due to submersion in water: (a) mixtures compacted at intermediate effort and cured at 28 days; and $(b)$ mixtures compacted at modified effort.

\section{CONCLUSÃO}

A imersão em água das misturas solo-grits, compactadas e curadas, influenciou significativamente os valores de resistência mecânica dessas misturas, a depender do tipo de ensaio empregado, tipo de solo, teor de grits, energia de compactação e período de cura. Quando confinadas (ensaio CBR), as misturas solo 1 -grits tiveram perdas máximas de resistência mecânica próximas de $20 \%$, e as misturas solo 2 -grits foram dependentes do teor de resíduo, de tal forma que, quanto maior o teor de grits, melhores os desempenhos mecânicos dessas misturas, observandose ganhos nos valores de CBR, devido à imersão em água, partir do teor de $16 \%$ de grits. Quando nãoconfinadas (ensaios de compressão não confinada), as misturas solo 1-grits atingiram perdas totais de resistência mecânica em alguns tratamentos, principalmente quando compactadas na energia modificada e não submetidas à períodos de cura ou curadas por sete dias; as menores perdas foram obtidas nas misturas curadas a 28 dias, devido ao tempo de ocorrência das reações pozolânicas. De forma análoga, as misturas solo 2-grits tiveram, na maioria dos tratamentos, perdas totais de integridade dos corposde-prova imersos em água, em razão da falta de ação cimentante do resíduo grits nas partículas do solo 2 , sendo as menores perdas associadas ao teor de $28 \%$ de grits nas misturas curadas a 7 e 28 dias.

\section{AGRADECIMENTOS}

Ao CNPq e à FAPEMIG, pelo apoio financeiro ao projeto, bem como à CAPES e à UFV, respectivamente, pela concessão de bolsa de doutorado e instalações físicas para a execução deste trabalho. Também, à empresa. Celulose Nipo Brasileira (CENIBRA S.A) pelo fornecimento do resíduo grits.

\section{REFERÊNCIAS}

\section{ASSOCIAÇÃO BRASILEIRA DE NORMAS TÉCNICAS - ABNT. NBR 10.004:}

Classificação de resíduos sólidos. Rio de Janeiro: 1987. 63p.

\author{
DEPARTAMENTO NACIONAL DE \\ INFRAESTRUTURA DE TRANSPORTES - DNIT. \\ ME 129: Solos: compactação \\ utilizando amostras não trabalhadas. \\ Rio de Janeiro: 1994a. 7p.
}

R. Árvore, Viçosa-MG, v.31, n.3, p.479-486, 2007 
DEPARTAMENTO NACIONAL DE INFRAESTRUTURA DE TRANSPORTES - DNIT. ME 216: Solo-cimento: determinação da relação entre o teor de umidade e a massa específica aparente. Rio de Janeiro: 1994b. 8p.

DEPARTAMENTO NACIONALDE INFRAESTRUTURA DE TRANSPORTES - DNIT. ME 201: Solo-cimento: compressão axial de corpos-de-prova cilíndricos: Método de ensaio. Rio de Janeiro: 1994c. 4p.

DEPARTAMENTO NACIONALDE INFRAESTRUTURA DE TRANSPORTES - DNIT. ME 202: Solo-cimento: moldagem e cura de corpos-de-prova cilíndricos: Método de ensaio. Rio de Janeiro: 1994d. 7p.

LIMA, D. C.; RÖHM, S. A.; BARBOSA, P. S. A. Estabilização dos solos III: mistura solocal para fins rodoviários. Viçosa, MG:

Universidade Federal de Viçosa, 1993. 46p.

(Publicação, 334).

MACHADO, C. C.; PEREIRA, R. S.; PIRES, J. M. M. Influência do tratamento térmico do resíduo sólido industrial (grits) na resistência mecânica de um latossolo para pavimentos de estradas florestais. Revista Árvore, v.27, n.4, p.543-550, 2003a.

MACHADO, C. C. et al. Classificação tecnológica de solos e resíduos industriais, com e sem tratamento térmico, para fins rodoviários.

Revista Árvore, v.27, n.5, p.657-668, 2003 b.
MACHADO.C. C. et al. Environmental behavior of soils and mixtures of soil - whitewash-mud. Revista Árvore, v.28, n.3, p.459-464, 2004.

PEREIRA, R. S.; MACHADO, C. C.; LIMA, D. C. Compactação de misturas solo-grits para emprego em estradas florestais: influência do tempo decorrido entre mistura e compactação na resistência mecânica. Revista Árvore, v.30, n.3, p.421-427, 2006.

PEREIRA, R. S. et al. Disposição final de resíduos industriais como estabilizantes químicos de solos de estradas florestais: análise ambiental. In: SIMPÓSIO BRASILEIRO SOBRE COLHEITAE TRANSPORTE FLORESTAL, 6., 2003, Belo Horizonte. Anais...Belo Horizonte: SIF/UFV, 2003. p.252-266.

ROHDE, L.; NÚÑEZ, W. P.; CERATTI, J. A. P. Utilização da escória de aciaria elétrica como material de pavimentação: variação das características mecânicas em função da composição granulométrica. In: REUNIÃO ANUAL DE PAVIMENTAÇÃO, 33., Florianópolis, 2001. Anais...Florianópolis: 2001. p.266-276.

SENÇO, W. Manual de técnicas de pavimentação. São Paulo: PINI, 1997. v.1. 174p.

TRINDADE, T. P.et al. Influência do tipo de cura (selada e exposta) e da imersão em água na resistência mecânica de misturas solo-RBI Grade $81 \mathrm{com}$ vistas a aplicações em estradas florestais. Revista Árvore, v.29, n.4, p.601-606, 2005. 